\title{
A Personalized Mobile Health Program for Type 2 Diabetes During the COVID-19 Pandemic: Single-Group Pre-Post Study
}

Ian Yi Han Ang ${ }^{1 *}$, BS, MA, MPhil, PhD; Kyle Xin Quan Tan ${ }^{1,2^{*}}$, MBBS, MPH; Clive Tan ${ }^{1,3}$, MBBS, MPH; Chiew Hoon Tan ${ }^{3}$, BSc; James Wei Ming Kwek ${ }^{3}$, MBBS, MMed; Joanne Tay ${ }^{2}$, MBBS, MPH; Sue Anne Toh ${ }^{2,4,5}$, MBBCHIR, $\mathrm{MA}, \mathrm{MSc}$

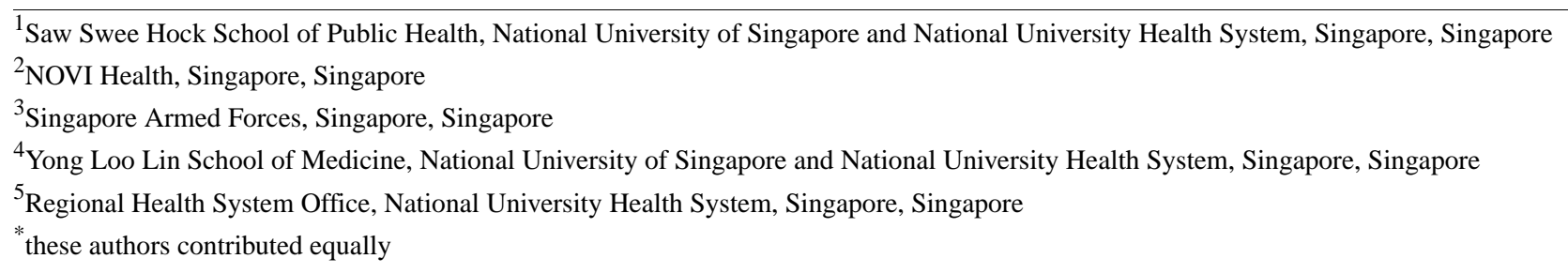

Corresponding Author:

Ian Yi Han Ang, BS, MA, MPhil, PhD

Saw Swee Hock School of Public Health

National University of Singapore and National University Health System

Tahir Foundation Building, 10th Floor

12 Science Drive 2

Singapore

Singapore

Phone: 6567791489

Email:yha2103@columbia.edu

\section{Abstract}

Background: With increasing type 2 diabetes prevalence, there is a need for effective programs that support diabetes management and improve type 2 diabetes outcomes. Mobile health (mHealth) interventions have shown promising results. With advances in wearable sensors and improved integration, mHealth programs could become more accessible and personalized.

Objective: The study aimed to evaluate the feasibility, acceptability, and effectiveness of a personalized mHealth-anchored intervention program in improving glycemic control and enhancing care experience in diabetes management. The program was coincidentally implemented during the national-level lockdown for COVID-19 in Singapore, allowing for a timely study of the use of mHealth for chronic disease management.

Methods: Patients with type 2 diabetes or prediabetes were enrolled from the Singapore Armed Forces and offered a 3-month intervention program in addition to the usual care they received. The program was standardized to include (1) in-person initial consultation with a clinical dietitian; (2) in-person review with a diabetes specialist doctor; (3) 1 continuous glucose monitoring device; (4) access to the mobile app for dietary intake and physical activity tracking, and communication via messaging with the dietitian and doctor; and (5) context-sensitive digital health coaching over the mobile app. Medical support was rendered to the patients on an as-needed basis when they required advice on adjustment of medications. Measurements of weight, height, and glycated hemoglobin $\mathrm{A}_{1 \mathrm{c}}\left(\mathrm{HbA}_{1 \mathrm{c}}\right)$ were conducted at 2 in-person visits at the start and end of the program. At the end of the program, patients were asked to complete a short acceptability feedback survey to understand the motivation for joining the program, their satisfaction, and suggestions for improvement.

Results: Over a 4-week recruitment period, 130 individuals were screened, the enrollment target of 30 patients was met, and 21 patients completed the program and were included in the final analyses; 9 patients were lost to follow-up (full data were not available for the final analyses). There were no differences in the baseline characteristics between patients who were included and excluded from the final analyses (age category: $P=.23$; gender: $P=.21$; ethnicity: $P>.99$; diabetes status category: $P=.52$, medication adjustment category: $P=.65 ; \mathrm{HbA}_{1 \mathrm{c}}$ category: $P=.69$; BMI: $P>.99$ ). The 21 patients who completed the study rated a mean of 9.0 out of 10 on the Likert scale for both satisfaction questions. For the Yes-No question on benefit of the program, all of the patients selected "Yes." Mean $\mathrm{HbA}_{1 \mathrm{c}}$ decreased from 7.6\% to 7.0\% $(P=.004)$. There were no severe hypoglycemia events 
(glucose level $<3.0 \mathrm{mmol} / \mathrm{L}$ ) reported. Mean weight decreased from $76.8 \mathrm{~kg}$ to $73.9 \mathrm{~kg}(P<.001)$, a mean decrease of $3.5 \%$ from baseline weight. Mean BMI decreased from $27.8 \mathrm{~kg} / \mathrm{m}^{2}$ to $26.7 \mathrm{~kg} / \mathrm{m}^{2}(P<.001)$.

Conclusions: The personalized mHealth program was feasible, acceptable, and produced significant reductions in $\mathrm{HbA}_{1 \mathrm{c}}$ $(P=.004)$ and body weight $(P<.001)$ in individuals with type 2 diabetes. Such mHealth programs could overcome challenges posed to chronic disease management by COVID-19, including disruptions to in-person health care access.

(JMIR Diabetes 2021;6(3):e25820) doi: 10.2196/25820

\section{KEYWORDS}

type 2 diabetes; prediabetic state; text messaging; mobile applications; glycated hemoglobin A; HbA1c; blood glucose; body mass index; mHealth; COVID-19; diabetes; intervention; self-management; chronic disease; outcome

\section{Introduction}

Close to half a billion people in the world live with type 2 diabetes, and this prevalence is expected to increase by $25 \%$ by 2030 [1]. An estimated 430,000 (14.4\% prevalence) Singapore residents aged 21 years and older had type 2 diabetes in 2015 , and it has been estimated that the number will grow to 820,000 in the year 2035 ( $22.7 \%$ prevalence), assuming no change to the current landscape [2]. In addition, an estimated 560,000 (18.6\% prevalence) Singapore residents in 2015 have prediabetes, of whom an estimated 490,000 (16.2\% prevalence) were undetected. Type 2 diabetes has been identified as a chronic disease whose patients persistently incur high health care costs [3]. Effective scalable prevention measures are thus urgently needed to prevent and better manage type 2 diabetes to reduce its burden.

Lifestyle and behavior modification interventions for the prevention and management of type 2 diabetes have been shown to be effective in reducing risk of disease progression $[4,5]$. Executed well, lifestyle and behavior modification intervention programs can even have long-term sustained beneficial effects in decreased diabetes incidence and associated complications [6]. Such programs have traditionally been structured with a high frequency of in-person group-based sessions over a long duration (at least 6 months) [4,5]. Such programs can require a sizeable multidisciplinary professional team to run, which is costly $[7,8]$, thereby limiting the scalability and sustainability of such interventions.

Simultaneously, many of these traditional lifestyle and behavior modification intervention programs have been found to have low participation rates [4] and high attrition [9]. Reasons for dropping out from such intervention programs include conflict between work schedules and center's hours of operation, distance to center, forgetfulness, lack of familiarity with the center and services, and apathy toward diabetes education [10]. Potential solutions to these barriers include running the program in the community [11,12], with reduced intensity [13], and leveraging mobile health (mHealth) interventions [14].

The use of mHealth for lifestyle and behavior modification interventions capitalizes on easily rolled out technologies to make communication and self-management education components easily accessible and independent of location. Over the years, mHealth interventions have progressed from using phone calls, text messages, and internet websites to, more recently, smartphone apps. The use of mHealth interventions for chronic disease care and management has been well-received with high acceptability and engagement [15-17]. In the care and management of type 2 diabetes, mHealth interventions have been successful in achieving improvements in clinical outcomes $[18,19]$. The use of adaptable feedback on behaviors with tailored messaging in mHealth interventions further allows for personalization according to the needs and preferences of patients $[20,21]$. Such a patient-centered approach of mHealth interventions could improve motivation in patients to make lifestyle and behavioral modifications and to sustain the changes made $[22,23]$.

The use of wearable sensors in mHealth interventions provides real-time tracking and monitoring in patients with type 2 diabetes. Self-monitoring of blood glucose level, either by finger-stick or continuous glucose monitoring (CGM) technology, has been shown to be useful in helping patients improve their diabetes control [24-27]. Blood glucose data logged in mHealth apps can be consolidated with app-recorded diet and physical activity data and have been found to help facilitate self-care in patients at risk of or with type 2 diabetes $[28,29]$. Drawing on advancements in technology, integration of various successful features could bring about synergistic improvements in mHealth interventions for the management of type 2 diabetes.

Given the increasing burden and cost of uncontrolled type 2 diabetes and related complications, there is a great urgency for scalable and effective solutions that reduce such a burden and cost [30,31]. In response to this need, a personalized mHealth-anchored intervention program was designed and implemented in patients with type 2 diabetes or prediabetes. This study aimed to evaluate the effectiveness and feasibility of this personalized mHealth program in improving glycemic control and enhancing care experience in diabetes management.

\section{Methods}

\section{Site and Population}

The program was conducted in Singapore, a city-state in tropical Southeast Asia with a population of 5.64 million people [32]. The patients were recruited from the Singapore Armed Forces in collaboration with their Headquarters Medical Corps. The Singapore Armed Forces provides primary health care services within military camps for its full-time service personnel and conscripts and a range of risk-based health screening programs for personnel in older age ranges. These older personnel with 
chronic health conditions are also free to obtain care from the national health care system outside of the Singapore Armed Forces.

The patients were recruited from active full-time service personnel and conscripts. Invitation to participate in the program was conducted by the Singapore Armed Forces' Headquarters Medical Corps through a series of intranet publicity advertisements posted over 4 weeks in February 2020. Interested patients were screened by the Headquarters Medical Corps and were enrolled into the program if they were interested and met the eligibility criteria (of having type 2 diabetes or prediabetes). The patients were deemed to have (1) type 2 diabetes, if they had glycated hemoglobin $\left(\mathrm{HbA}_{1 \mathrm{c}}\right) \geq 6.5 \%$ in the past 1 year or if they were on medication for type 2 diabetes, or (2) prediabetes, if they had an $\mathrm{HbA}_{1 \mathrm{c}}$ level in the range $5.7 \%$ to $6.4 \%$ in the past year, and they were not taking any medications for type 2 diabetes. The enrollment target was set at 30 individuals, which was deemed to be sufficient to assess the feasibility and acceptability of such an intervention in a pilot program [33,34].

\section{Intervention Program}

The Singapore Armed Forces' Headquarters Medical Corps worked with NOVI Health, a health care technology start-up based in Singapore, to provide their proprietary mHealth program to the enrolled population.

All eligible patients were offered the 3-month intervention program in addition to the usual care that they received for their type 2 diabetes or prediabetes (Figure 1). The program was standardized to include the following components: (1) in-person initial consultation with a clinical dietitian that served as a health coach, (2) in-person review with a diabetes specialist doctor, (3) 1 Abbott Freestyle Libre CGM device that provided monitoring in the first 2 weeks, (4) access to the mobile app that allowed dietary intake and physical activity tracking and communication via text messaging with the dietitian and doctor, and (5) context-sensitive digital health coaching provided by the dietitian over the mobile app (Figure 2).

Figure 1. Intervention program timeline and protocol. *Recruitment with a series of publicity advertisements on the Singapore Armed Forces' intranet. ${ }^{\wedge}$ Glycated hemoglobin level $\left(\mathrm{HbA}_{1 \mathrm{c}}\right)$ was measured if there was no valid reading within the prior 3 months.

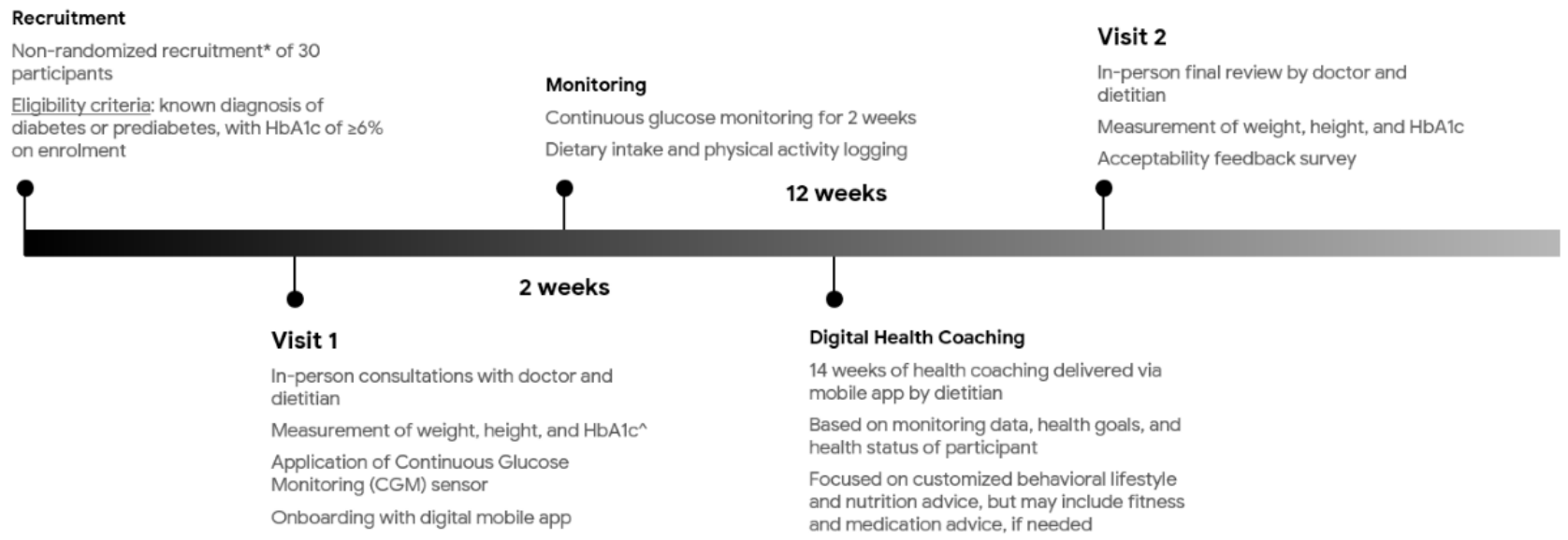

Figure 2. Screenshots of mobile app dashboard with diet and physical activity goals, real-time continuous glucose monitoring data, dietary intake and physical activity logs, and personalized recommendations delivered through the messaging function in the mobile app.
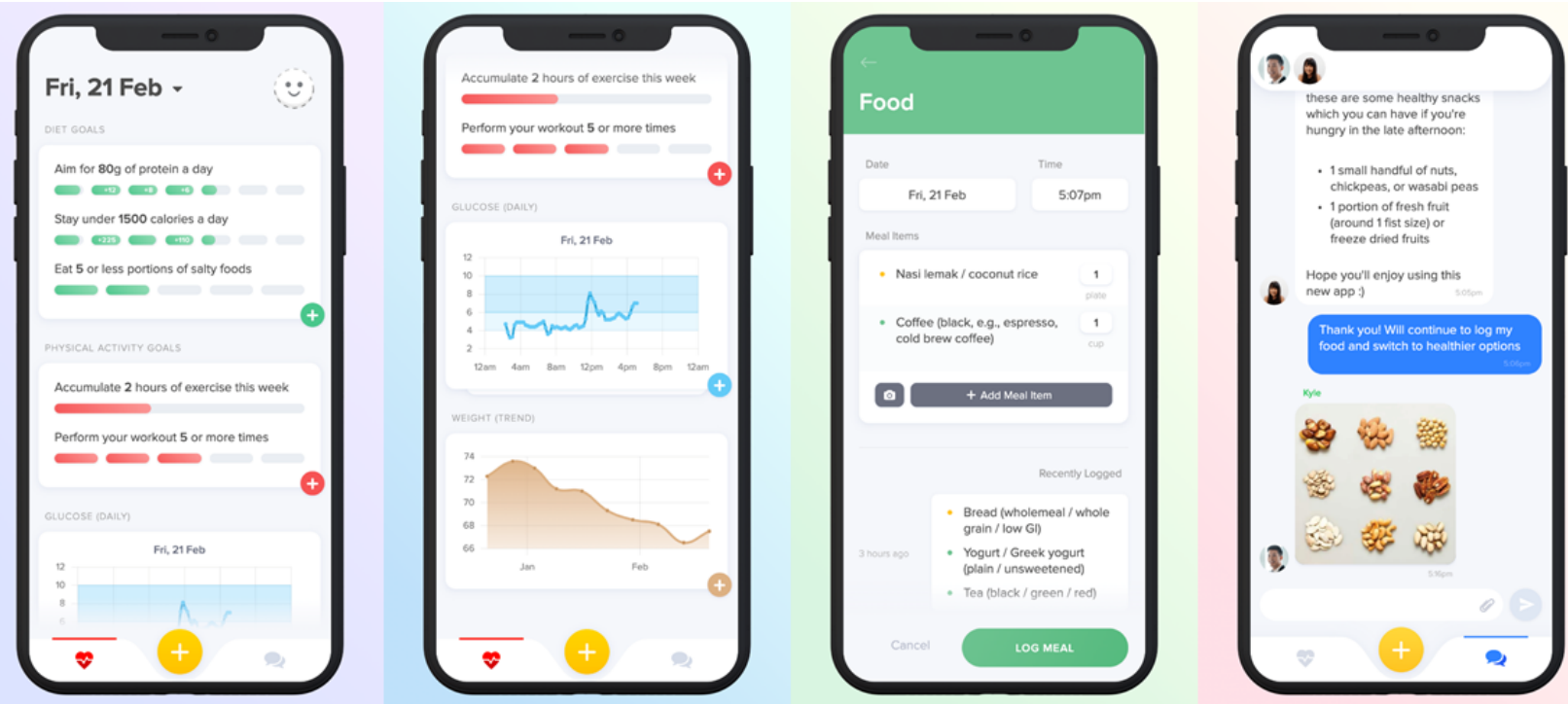
In the first in-person visit to the clinic (Visit 1), the patients had a consultation with the dietitian to set their health goals and discuss behavioral lifestyle changes that could be made. The patients also had a consultation with the diabetes specialist doctor, which allowed for the review of comorbidities and medication regime. The patients were also provided with 1 CGM device and were guided on how to use the device for glucose monitoring and how to provide the care team with access to their real-time CGM data.

In the subsequent 3 months after Visit 1, the patients were free-living and used the mobile app to log their dietary intake and physical activity. The dietitian and doctor were able to view the CGM, dietary intake, and physical activity data together with available information on the patients' health status (information on $\mathrm{HbA}_{1 \mathrm{c}}$, comorbidities, and medication regime). This allowed them to deliver timely personalized recommendations through the messaging function of the mobile app. The health coaching via the mobile app was led by the clinical dietitian, with input from the fitness coaches provided when needed, and with medical oversight from the reviewing diabetes specialist doctor. Medical support via the mobile app was also provided to the patients on an as-needed basis (if they experienced hypoglycemia requiring medication adjustments or if they required advice on the adjustment of medications, etc). After 3 months, the patients returned to the clinic for their second in-person visit (Visit 2) to meet with the diabetes specialist doctor and dietitian for final review.

Patient recruitment for the program started in February 2020 and the program ran from March 2020 to June 2020. The recruitment period and the first month of the intervention program corresponded with a worsening COVID-19 situation in Singapore through the months of February and March 2020. This culminated in a national-level lockdown, which started on April 7, 2020 and ended on June 1, 2020, coinciding with the second and third months of the intervention program. The 2 in-person visits to the clinic (Visits 1 and 2) happened to have been scheduled in the periods before and after the lockdown in Singapore and were, therefore, not impacted.

\section{Outcome Measurements}

Measurements of weight, height, and $\mathrm{HbA}_{1 \mathrm{c}}$ were conducted at Visits 1 and 2. Weight and height were measured by a trained nurse, using a Surgico Healthweigh machine. At the end of the program at Visit 2, the patients were asked to complete a short acceptability feedback survey to understand the motivation for joining the program, their satisfaction, and suggestions for improvement. The question on motivation, "What was your primary motivation for signing up for this program?" had 4 options: "1. Wanted to get my diabetes under control, 2. Wanted to get dietary advice for my diabetes, 3 . Wanted to lose weight, 4. Was asked to participate by HQMC." There were 2 satisfaction questions rated on a 10-point Likert scale, "How satisfied were you with the program?" and "How likely are you to recommend this program to your colleague?" A fourth question "Do you think that other servicemen would benefit from this program?" was a Yes-No question asking the patients on whether the program would be beneficial to others.

\section{Data Analysis}

Patients were considered to have completed the study and included in the final outcomes analyses if they had completed the full 14 weeks of the intervention program, with weight, height, and $\mathrm{HbA}_{1 \mathrm{c}}$ measurements at baseline (Visit 1) and at completion of the program (Visit 2). Means were calculated for continuous baseline characteristic variables. Due to nonnormality of data, the Wilcoxon signed rank test was used to compare means between those who completed the study and those that were lost to follow-up and excluded. Proportions were calculated for baseline characteristics that were categorical variables. The Fisher exact test was used if counts were less than 5 to compare distributions of those who completed the study and those who were lost to follow-up and excluded.

The final analyses of main outcomes of interest for acceptability and effectiveness were limited to only the those who completed the study. For the outcomes of $\mathrm{HbA}_{1 \mathrm{c}}$, weight, and BMI, the patients were further split for subgroup analyses: (1) by baseline $\mathrm{HbA}_{1 \mathrm{c}} \leq 7 \%$ or $>7 \%$, and (2) by baseline $\mathrm{BMI}<27.5 \mathrm{~kg} / \mathrm{m}^{2}$ (normal and overweight) or $\geq 27.5 \mathrm{~kg} / \mathrm{m}^{2}$ (obese). The $\mathrm{HbA}_{1 \mathrm{c}}$ cut-off was selected based on the $\mathrm{HbA}_{1 \mathrm{c}}$ threshold set by major clinical guidelines for what is considered good diabetes control [35-37], and the BMI threshold was selected based on what is considered obese in the Asian population [38]. Due to nonnormality of data, the Wilcoxon signed rank test was used for the paired comparisons of the main outcomes at Visit 1 and Visit 2, with significance level set at $\alpha=.05$. Analyses were conducted in $\mathrm{R}$ (version 3.6.1). Means and standard deviations of the main outcomes are presented, along with $P$ values, where applicable. Calculation of type II beta errors were also conducted for the main outcomes of interest using $\mathrm{G}^{*}$ Power (version 3.1.9.4), for a 2-tailed test according to a Laplace parent distribution and $\alpha=.05$. Beta errors $>.2$ are indicated.

\section{Ethics Approval}

This study was conducted as part of a program evaluation. The data collected were presented at the Singapore Armed Forces' Joint Medical Committee for Research and approved for exemption from full review at the Institutional Review Board.

\section{Results}

\section{Baseline Characteristics}

Over the 4-weeks recruitment period in February 2020, there were 130 individuals screened, of whom 30 met eligibility criteria and were interested in participating in the program. Of the 30 enrolled patients, 7 were lost to follow-up, and 2 had completed the program but did not have complete measurements from Visit 2. As such, 21 patients were included in the final outcome analyses. There were no significant differences in any of the baseline characteristics (age category: $P=.23$; gender: $P=.21$; ethnicity: $P>.99$; diabetes status category: $P=.52$, medication adjustment category: $P=.65$ HbA $_{1 \mathrm{c}}$ category: $P=.69$; BMI: $P>.99)$ between the patients who were excluded and those who were included in the final outcome analyses (Table 1). The majority of the patients were male. The majority of the patients had diabetes; the patients who had diabetes were all on glucose 
lowering medication upon enrollment into the program. While there were patients who were on insulin therapy upon entry into the program, no patient started insulin during the program. There were 5 patients who had their medication adjusted. One patient's insulin dosage was reduced, 2 patients had their medication (sulfonylurea) switched to another oral antihyperglycemic medication to reduce hypoglycemic risk, and 2 patients had 1 oral antihyperglycemic medication added to their existing regime. Approximately two-thirds of the patients had baseline $\mathrm{HbA}_{1 \mathrm{c}}>7 \%$, and approximately half had BMIs that placed them in the obese category.

Table 1. Baseline characteristics of all enrolled patients, patients lost to follow-up, and patients who completed the program and were included in the final analyses.

\begin{tabular}{|c|c|c|c|c|}
\hline Characteristics & All recruited $(n=30)$ & Lost to follow-up (n=9) & Completed $(\mathrm{n}=21)$ & $P$ value \\
\hline Age (years), mean (range) & $49.1(21-64)$ & $43.7(21-61)$ & $51.4(32-64)$ & .054 \\
\hline Age, n (\%) & & & & .23 \\
\hline$<50$ years & $17(57)$ & $7(78)$ & $10(48)$ & \\
\hline$\geq 50$ years & $13(43)$ & $2(22)$ & $11(52)$ & \\
\hline Gender, n (\%) & & & & .21 \\
\hline Female & $9(30)$ & $1(11)$ & $8(38)$ & \\
\hline Male & $21(70)$ & $8(89)$ & $13(62)$ & \\
\hline Ethnicity, n (\%) & & & & $>.99$ \\
\hline Chinese & $24(80)$ & $8(89)$ & $16(76)$ & \\
\hline Malay & $1(3)$ & $0(0)$ & $1(5)$ & \\
\hline Indian/Pakistani & $5(17)$ & $1(11)$ & $4(19.0)$ & \\
\hline Diabetes status, n (\%) & & & & .52 \\
\hline Prediabetes & $2(7)$ & $1(11)$ & $1(5)$ & \\
\hline Type 2 diabetes & $28(93)$ & $8(89)$ & $20(95)$ & \\
\hline Medication adjustments, $\mathbf{n}(\%)$ & & & & .65 \\
\hline Adjusted & $8(27)$ & $3(33)$ & $5(24)$ & \\
\hline Not adjusted & $22(73)$ & $6(67)$ & $16(76)$ & \\
\hline Baseline $\mathrm{HbA}_{1 \mathrm{c}}{ }^{\mathrm{a}}(\%)$, mean & 7.7 & 7.9 & 7.6 & $>.99$ \\
\hline Baseline $\mathrm{HbA}_{1 \mathrm{c}}$ category, $\mathrm{n}(\%)$ & & & & .69 \\
\hline$\leq 7 \%$ & $11(37)$ & $4(44)$ & $7(33)$ & \\
\hline$>7 \%$ & $19(63)$ & $5(56)$ & $14(67)$ & \\
\hline Baseline $\mathrm{BMI}^{\mathrm{b}}\left(\mathrm{kg} / \mathrm{m}^{2}\right)$, mean & 27.9 & 28.2 & 27.8 & .96 \\
\hline Baseline BMI category, n (\%) & & & & $>.99$ \\
\hline$<27.5 \mathrm{~kg} / \mathrm{m}^{2}$ & $15(50)$ & $4(44)$ & $11(52)$ & \\
\hline$\geq 27.5 \mathrm{~kg} / \mathrm{m}^{2}$ & $15(50)$ & $5(56)$ & $10(48)$ & \\
\hline Baseline weight $(\mathrm{kg})$, mean & 77.7 & 79.7 & 76.8 & .82 \\
\hline
\end{tabular}

${ }^{\mathrm{a}} \mathrm{HbA}_{1 \mathrm{c}}$ : glycated hemoglobin.

${ }^{\mathrm{b}} \mathrm{BMI}$ : body mass index.

\section{Acceptability Feedback}

For the multiple-choice question on motivation, $48 \%$ of patients (10/21) selected "Wanted to get my diabetes under control," $19 \%$ of patients $(4 / 21)$ selected "Wanted to get dietary advice for my diabetes," 3 (14\% of patients (3/21) patients selected "Wanted to lose weight," and 19\% of patients (4/21) selected "Was asked to participate by HQMC." The patients rated a mean of 9.0 out of 10 on the Likert scale for both satisfaction questions. For the Yes-No question on the benefit of the program, all patients selected "Yes."

\section{Effectiveness Outcomes}

For all 21 who completed the study, mean $\mathrm{HbA}_{1 \mathrm{c}}$ decreased from $7.6 \%$ to $7.0 \%(P=.004)$ (Table 2). Mean weight had decreased from $76.8 \mathrm{~kg}$ to $73.9 \mathrm{~kg}(P<.001)$, which was a mean decrease of $3.5 \%$ (SD 3.2\%) from baseline. Mean BMI had decreased from $27.8 \mathrm{~kg} / \mathrm{m}^{2}$ to $26.7 \mathrm{~kg} / \mathrm{m}^{2}(P<.001)$. 
Table 2. Comparison of $\mathrm{HbA}_{1 \mathrm{c}}$, weight, and BMI at Visit 1 and Visit 2 for all patients who completed the study.

\begin{tabular}{llll}
\hline Outcome & Visit 1, mean (SD) & Visit 2, mean (SD) & $P$ value \\
\hline $\mathrm{HbA}_{1 \mathrm{c}}^{\mathrm{a}}(\%)$ & $7.6(1.1)$ & $7.0(0.8)$ & .004 \\
Weight $(\mathrm{kg})$ & $76.8(15.6)$ & $73.9(13.8)$ & $<.001$ \\
$\mathrm{BMI}^{\mathrm{b}}\left(\mathrm{kg} / \mathrm{m}^{2}\right)$ & $27.8(5.4)$ & $26.7(4.8)$ & $<.001$ \\
\hline
\end{tabular}

${ }^{\mathrm{a}} \mathrm{HbA}_{1 \mathrm{c}}$ : glycated hemoglobin.

${ }^{\mathrm{b}} \mathrm{BMI}$ : body mass index.

\section{Subgroup Analyses by Baseline $\mathrm{HbA}_{1 \mathrm{c}}$ Category}

For patients who had baseline $\mathrm{HbA}_{1 \mathrm{c}} \leq 7 \%$, there was no statistically significant change in $\mathrm{HbA}_{1 \mathrm{c}}$ upon completion of the 3-month intervention program $(P=.67)$, but the beta error was found to be $>.2$ (Table 3). However, mean weight decreased from $75.0 \mathrm{~kg}$ to $73.0 \mathrm{~kg}(P=.02$; mean decrease $3.9 \%$, SD $3.7 \%)$.
Mean BMI decreased from $26.8 \mathrm{~kg} / \mathrm{m}^{2}$ to $26.1 \mathrm{~kg} / \mathrm{m}^{2}(P=.02)$. For the patients who had baseline $\mathrm{HbA}_{1 \mathrm{c}}>7 \%$, mean $\mathrm{HbA}_{1 \mathrm{c}}$ decreased from $8.1 \%$ to $7.2 \%(P=.005)$. Mean weight also decreased from $77.8 \mathrm{~kg}$ to $74.3 \mathrm{~kg}(P=.006)$, which was a mean decrease of $2.5 \%$ (SD 1.8\%) from the baseline weight. Mean BMI decreased from $28.3 \mathrm{~kg} / \mathrm{m}^{2}$ to $27.1 \mathrm{~kg} / \mathrm{m}^{2}(P=.006)$.

Table 3. Comparison of Visit 1 and Visit 2 characteristics for patients who had baseline $\mathrm{HbA}_{1 \mathrm{c}} \leq 7 \%$ or $>7 \%$.

\begin{tabular}{|c|c|c|c|c|c|c|}
\hline \multirow[t]{2}{*}{ Outcome } & \multicolumn{3}{|c|}{ Baseline $\mathrm{HbA}_{1 \mathrm{c}} \leq 7 \%(\mathrm{n}=7)$} & \multicolumn{3}{|c|}{ Baseline $\mathrm{HbA}_{1 \mathrm{c}}>7 \%(\mathrm{n}=14)$} \\
\hline & Visit 1, mean (SD) & Visit 2, mean (SD) & $P$ value & Visit 1 , mean (SD) & Visit 2, mean (SD) & $P$ value \\
\hline $\mathrm{HbA}_{1 \mathrm{c}}{ }^{\mathrm{a}}(\%)$ & $6.7(0.3)$ & $6.6(0.6)$ & $.67^{b}$ & $8.1(1.0)$ & $7.2(0.8)$ & .005 \\
\hline Weight (kg) & $75.0(13.5)$ & $73.0(12.2)$ & .02 & $77.8(16.9)$ & $74.3(14.9)$ & .006 \\
\hline $\mathrm{BMI}^{\mathrm{c}}\left(\mathrm{kg} / \mathrm{m}^{2}\right)$ & $26.8(5.1)$ & $26.1(4.8)$ & .02 & $28.3(5.7)$ & $27.1(4.9)$ & .006 \\
\hline
\end{tabular}

${ }^{\mathrm{a}} \mathrm{HbA}_{1 \mathrm{c}}$ : glycated hemoglobin.

$\mathrm{b}_{\text {Type II beta error }>.2 \text {. }}$.

${ }^{\mathrm{c}} \mathrm{BMI}$ : body mass index.

\section{Subgroup Analyses by Baseline BMI Category}

There were no statistically significant changes in $\mathrm{HbA}_{1 \mathrm{c}}$, weight, or BMI for patients who were in the normal and overweight BMI category, after the intervention in Visit 2, but beta errors were found to be >.2 (Table 4). For the patients who were in the obese BMI category, mean $\mathrm{HbA}_{1 \mathrm{c}}$ decreased from $7.6 \%$ to $6.8 \%(P=.006)$. Mean weight also decreased from $89.3 \mathrm{~kg}$ to $84.1 \mathrm{~kg}(P=.002$, mean decrease 5.9\%, SD 2.2\%). Mean BMI decreased from $32.5 \mathrm{~kg} / \mathrm{m}^{2}$ to $30.6 \mathrm{~kg} / \mathrm{m}^{2}(P=.002)$.

Table 4. Comparison of Visit 1 and Visit 2 characteristics for patients who had baseline BMI $<27.5 \mathrm{~kg} / \mathrm{m}^{2}$ (normal and overweight) or $\geq 27.5 \mathrm{~kg} / \mathrm{m}^{2}$ (obese).

\begin{tabular}{|c|c|c|c|c|c|c|}
\hline \multirow[t]{2}{*}{ Outcome } & \multicolumn{3}{|c|}{ Normal and overweight $(\mathrm{n}=11)$} & \multicolumn{3}{|l|}{ Obese $(n=10)$} \\
\hline & Visit 1 , mean (SD) & Visit 2, mean (SD) & $P$ value & Visit 1, mean (SD) & Visit 2, mean (SD) & $P$ value \\
\hline $\mathrm{HbA}_{1 \mathrm{c}}{ }^{\mathrm{a}}(\%)$ & $7.7(1.3)$ & $7.3(0.9)$ & $.14^{\mathrm{b}}$ & $7.6(0.9)$ & $6.8(0.6)$ & .006 \\
\hline Weight (kg) & $65.5(8.7)$ & $64.6(8.1)$ & $.07^{\mathrm{b}}$ & $89.3(11.1)$ & $84.1(11.2)$ & .002 \\
\hline $\mathrm{BMI}^{\mathrm{c}}\left(\mathrm{kg} / \mathrm{m}^{2}\right)$ & $23.5(2.1)$ & $23.2(2.03)$ & $.07^{\mathrm{b}}$ & $32.5(3.6)$ & $30.6(3.7)$ & .002 \\
\hline
\end{tabular}

${ }^{\mathrm{a}} \mathrm{HbA}_{1 \mathrm{c}}$ : glycated hemoglobin.

${ }^{\mathrm{b}}$ Type II beta error $>.2$.

${ }^{\mathrm{c}} \mathrm{BMI}$ : body mass index.

\section{Complications}

During the study, the patients had no hospitalization episodes for any diabetes-related complications. There were no severe hypoglycemia (glucose level $<3 \mathrm{mmol} / \mathrm{L}$ ) events observed or reported.

\section{Discussion}

\section{General}

This study evaluated a real-world personalized mHealth-anchored intervention program for feasibility, acceptability, and effectiveness for diabetes management. The 
program garnered a lot of interest and the enrollment target was met fairly quickly (in less than a month). The program was implemented as planned in spite of the disruptions from COVID-19. The program also received high patient ratings of satisfaction and perceived benefit from participation in the program. The patients achieved a significant reduction in $\mathrm{HbA}_{1 \mathrm{c}}$ in 3 months, ending the program with an average $\mathrm{HbA}_{1 \mathrm{c}}$ of $7 \%$. Reduction of $\mathrm{HbA}_{1 \mathrm{c}}$ levels to $\leq 7 \%$ is consistent with the glycemic target set by most clinical guidelines $[35,36]$ and has been shown to reduce microvascular [39-43] and macrovascular [44] complications in individuals with type 2 diabetes. Patients in the study also achieved weight loss over 3 months that met the clinically significant threshold of 3\% [45,46]. Such reductions have been observed to lead to improvements in cardiovascular risk factors such as glycemic control, systolic and diastolic blood pressure, as well as with respect to low-density lipoprotein and high-density lipoprotein cholesterol levels [47].

The improvements observed were achieved in patients who had known type 2 diabetes and prediabetes and who were receiving usual care and on existing medications. This suggests that there could be a role for a personalized mHealth program for patients with diabetes, even those receiving usual medical care for their diabetes. Such a program could improve control of diabetes and further reduce the risk of microvascular and macrovascular complications. In the subgroups of patients with glycemic and BMI measures above the ideal range, the impact of the personalized mHealth program was even greater. These results were not unexpected as the patients with starting $\mathrm{HbA}_{1 \mathrm{c}}$ and weight values that were further from target were likely to have more room for improvement. The mHealth program could benefit most individuals with diabetes; targeting the program at individuals with higher $\mathrm{HbA}_{1 \mathrm{c}}$ or higher $\mathrm{BMI}$ would yield greater improvements in both $\mathrm{HbA}_{1 \mathrm{c}}$ and $\mathrm{BMI}$.

\section{Diabetes Management Programs}

Traditionally, diabetes management programs that supplement usual care for individuals with diabetes have focused on enhancing support and education, improving nutrition, and increasing physical activity with a structured curriculum-based approach [4]. Such intervention programs are usually conducted in-person and have been shown to be effective in improving glycemic control. In the Look AHEAD trial [48], intensive lifestyle intervention components involved group and individual meetings to achieve and maintain weight loss through decreased caloric intake and increased physical activity. The trial achieved an $\mathrm{HbA}_{1 \mathrm{c}}$ reduction of $0.7 \%$ and weight loss of $8.6 \%$ over 1 year [48]. In recent years, mHealth lifestyle intervention programs have emerged, bringing convenience and accessibility to individuals with diabetes, achieving $\mathrm{HbA}_{1 \mathrm{c}}$ reductions of approximately $0.3 \%$ to $0.5 \%[18,19,49-51]$ and insignificant changes in weight loss $[19,49,51]$.

The personalized mHealth program in this study combined health coach-led personalized lifestyle intervention with medical support by a specialist doctor, the use of CGM, and integrated delivery through a mobile app. The medical support allowed for medication adjustments where beneficial, for example, optimizing the timing of administration of the medication to more effectively suit the lifestyle patterns of the patient. However, it is important to note that, in this study, there were no major adjustments of medications, such as initiating patients on insulin, that could have confounded the improvements observed. This is in contrast to another feasibility study with the same mHealth components, in which it was not possible to determine if improvements were due to intensification of medical therapy or from the other components of the intervention program [52].

The mobile app and CGM allowed the real-time tracking of diet, physical activity, and glucose, for interventions that were highly personalized, context sensitive, and delivered in a timely manner. Visualization of their own data, coupled with remote monitoring and actionable insights from trusted experts through the mobile app to make sense of that data, could enable the patients to appreciate the impact of their behaviors on their own health parameters. This could have further empowered and reinforced the user to implement behaviors that improve their health on a continuous, real-time basis in between clinic visits, with a low risk of adverse events such as hypoglycemia. The integrated solution incorporating medical support, CGM, and lifestyle care delivery through a mobile app likely accounted for the intervention in this study achieving results comparable to those reported in other diabetes lifestyle intervention programs, in a far shorter period of 3 months.

Based on the responses from the survey at the end of the program, patients found this personalized mHealth program to be beneficial in improving their diabetes control. Patients also reported that they were satisfied with the personalized mHealth program. These results suggested that patients found value in the mHealth program and were also receptive to the program. As there was no glycemic threshold effect, participation in a personalized mHealth program could be recommended to most individuals with diabetes or prediabetes, with the understanding that greater clinical improvement is seen with poorer starting glycemic control.

\section{COVID-19 and Implications on Chronic Disease Management}

This program was conducted against the backdrop of a worsening COVID-19 pandemic, which saw Singapore undergo a national-level lockdown, termed circuit breaker, from April 7, 2020 to June 1, 2020. This coincided with the mHealth-anchored digital coaching phase of the program. During this period, there were widespread closures, of premises such as nonessential workplaces, schools, exercise and recreational facilities, and places of worship, along with the prohibition of all social gatherings [53]. Essential services in health care, transport, cleaning, food services, and supply chains remained open, but on a reduced capacity basis. This had several implications on the health and diabetes control of the patients.

With the closure of sports facilities, many of the patients who performed their physical activity in these locations were unable to continue doing so. Closure of workplaces and recreational facilities, as well as banning of social gatherings, meant that patients left their homes less and commuted less, resulting in lower physical activity levels [54]. The stress of being under 
lockdown may also have increased the consumption of ultra-processed food, which can be detrimental to diabetes control. While it is too early to assess the impact of the lockdown on diabetes control, experts anticipate a negative impact on weight as well as glycemic control $[55,56]$.

During the circuit breaker period, the patients also had greater difficulty accessing health care. Many of the patients had their regular reviews with their primary care physicians postponed. Some of the patients in critical operational roles were confined to military camps, with some reporting difficulties getting refills of certain medications from their external health care providers, and in some instances, difficulties in communicating via the mobile app due to certain camp security restrictions. These health care access issues would have negatively impacted the patients' diabetes care and control during this period.

The patients in this study experienced clinically significant improvements in their glycemic control $(P=.004)$, weight $(P<.001)$, and BMI $(P<.001)$. This was in spite of the anticipated worsening of weight and glycemic control due to decreased physical activity, poorer diet, and lack of access to health care due to a national-level lockdown [54-56]. This highlights the role that a diabetes solution with an mHealth component can play in improving the management of chronic diseases, such as type 2 diabetes, especially during periods where there are barriers to accessing health care in person.

\section{Strengths and Limitations}

This study evaluated a real-world context-sensitive mHealth-anchored intervention program with free-living patients. The program also coincidentally began during the start of the COVID-19 pandemic, with the bulk of the encounters occurring during the national-level lockdown in Singapore. This allowed for a timely study of the use of mHealth for chronic disease management just as the world needed to move toward embracing more digital solutions to limit in-person interactions.

A limitation of this study was that the program was conducted only with military personnel, which could have been expanded to include other professions so that the results could be more generalizable. However, the focus on military personnel could inform specific occupational policy changes to improve chronic disease prevention and management for active military personnel [57] and could reduce productivity lost among active personnel [58].
Another limitation was that the study consisted of a single intervention arm with no control group. Without a control group, there is a possibility that patients not undergoing the same program might still experience the same improvements with usual care during the same time period. However, this study demonstrated the feasibility of the program and also provided pilot data that can pave the way for future studies. Further explorations could be done on the improvements of the personalized mHealth program intervention and its various components.

Close to one-third of the patients had dropped out of the program. However, this was not higher than expected for a 3-month program, and we did not observe any systemic differences between the patients who completed the program compared to those who dropped out analyses (age category: $P=.23$; gender: $P=.21$; ethnicity: $P>.99$; diabetes status category: $P=.52$, medication adjustment category: $P=.65 ; \mathrm{HbA}_{1 \mathrm{c}}$ category: $P=.69$; BMI: $P>.99$ ). In spite of the small sample size, there was sufficient power for differences to be detected in the main analyses. However, there was insufficient power for a few of the subgroup analyses (beta errors were found to be >.2).

The patients were also only followed-up for 3 months until the end of the program; therefore, long-term effects of the program are unknown. This is a limitation commonly found in the review of other mHealth interventions [18,49,51], but there have been some promising indications of positive long-term outcomes [59]. This warrants additional follow-up investigations in future studies to explore whether effects are sustained after the program has ended, and whether some components could be implemented periodically in a cost-effective way to maintain the improvements achieved.

\section{Conclusion}

The personalized mHealth-anchored intervention program demonstrated feasibility and acceptability and was able to produce significant reductions in $\mathrm{HbA}_{1 \mathrm{c}}(P=.004)$ and body weight $(P<.001)$ in individuals with type 2 diabetes, in addition to usual care. The results also suggested that a program with a strong mHealth component could overcome challenges posed by COVID-19 to chronic disease management, including disruptions to in-person health care access. Further investigation is warranted to test the persistence of the results and the use of such digital therapeutics as a scalable solution to address the burden of diabetes.

\section{Acknowledgments}

The intervention program was a contracted health service paid for by the Singapore Armed Forces. Funding for the publication of this manuscript was provided by the Singapore Ministry of Health's National Medical Research Council Centre Grant Programme (grant number NMRC/CG/C026/2017_NUHS) for SPHERiC (the Singapore Population Health Improvement Centre). We would like to acknowledge senior dietitian Ruth Ho and staff nurse Liu Qing for their contributions to the delivery of the intervention program, as well as Nabilah Rahman for providing statistical advice.

\section{Authors' Contributions}

KTXQ, SAT, TCH, and CT were responsible for the design of the intervention program. TCH and JT assisted with recruitment of patients for the program and operational aspects of the implementation of the program. IYHA was responsible for data analysis. IYHA and KTXQ wrote the first draft of the manuscript. All authors provided input, edited, and approved the final draft of this paper. 


\section{Conflicts of Interest}

KTXQ, JT, and SAT are cofounders and shareholders of NOVI Health. IYHA, CT, TCH, and JWMK declare no conflicts of interest.

\section{References}

1. Saeedi P, Petersohn I, Salpea P, Malanda B, Karuranga S, Unwin N, IDF Diabetes Atlas Committee. Global and regional diabetes prevalence estimates for 2019 and projections for 2030 and 2045: results from the International Diabetes Federation Diabetes Atlas, 9 edition. Diabetes Res Clin Pract 2019 Nov;157:107843. [doi: 10.1016/j.diabres.2019.107843] [Medline: $\underline{31518657]}$

2. Wong LY, Toh MPHS, Tham LWC. Projection of prediabetes and diabetes population size in Singapore using a dynamic Markov model. J Diabetes 2017 Jan;9(1):65-75. [doi: 10.1111/1753-0407.12384] [Medline: 26849033]

3. Ng SHX, Rahman N, Ang IYH, Sridharan S, Ramachandran S, Wang DD, et al. Characterising and predicting persistent high-cost utilisers in healthcare: a retrospective cohort study in Singapore. BMJ Open 2020 Jan 06;10(1):e031622 [FREE Full text] [doi: 10.1136/bmjopen-2019-031622] [Medline: 31911514]

4. Aziz Z, Absetz P, Oldroyd J, Pronk NP, Oldenburg B. A systematic review of real-world diabetes prevention programs: learnings from the last 15 years. Implement Sci 2015 Dec 15;10:172 [FREE Full text] [doi: 10.1186/s13012-015-0354-6] [Medline: 26670418]

5. Chrvala CA, Sherr D, Lipman RD. Diabetes self-management education for adults with type 2 diabetes mellitus: a systematic review of the effect on glycemic control. Patient Educ Couns 2016 Dec;99(6):926-943 [FREE Full text] [doi: 10.1016/j.pec.2015.11.003] [Medline: 26658704]

6. Haw JS, Galaviz KI, Straus AN, Kowalski AJ, Magee MJ, Weber MB, et al. Long-term sustainability of diabetes prevention approaches: a systematic review and meta-analysis of randomized clinical trials. JAMA Intern Med 2017 Dec 01;177(12):1808-1817. [doi: 10.1001/jamainternmed.2017.6040] [Medline: 29114778]

7. Lawlor MS, Blackwell CS, Isom SP, Katula JA, Vitolins MZ, Morgan TM, et al. Cost of a group translation of the Diabetes Prevention Program: healthy living partnerships to prevent diabetes. Am J Prev Med 2013 Apr;44(4 Suppl 4):S381-S389 [FREE Full text] [doi: 10.1016/j.amepre.2012.12.016] [Medline: 23498303]

8. Vojta D, Koehler TB, Longjohn M, Lever JA, Caputo NF. A coordinated national model for diabetes prevention: linking health systems to an evidence-based community program. Am J Prev Med 2013 Apr;44(4 Suppl 4):S301-S306. [doi: 10.1016/j.amepre.2012.12.018] [Medline: 23498291]

9. Norris SL, Engelgau MM, Narayan KM. Effectiveness of self-management training in type 2 diabetes: a systematic review of randomized controlled trials. Diabetes Care 2001 Mar;24(3):561-587. [Medline: 11289485]

10. Gucciardi E, Demelo M, Offenheim A, Stewart DE. Factors contributing to attrition behavior in diabetes self-management programs: a mixed method approach. BMC Health Serv Res 2008 Feb;8:33 [FREE Full text] [doi: 10.1186/1472-6963-8-33] [Medline: 18248673]

11. Ackermann RT, Finch EA, Brizendine E, Zhou H, Marrero DG. Translating the Diabetes Prevention Program into the community. the DEPLOY pilot study. Am J Prev Med 2008 Oct;35(4):357-363 [FREE Full text] [doi: 10.1016/j.amepre.2008.06.035] [Medline: 18779029]

12. Lipscomb ER, Finch EA, Brizendine E, Saha CK, Hays LM, Ackermann RT. Reduced 10-year risk of coronary heart disease in patients who participated in a community-based diabetes prevention program: the DEPLOY pilot study. Diabetes Care 2009 Mar;32(3):394-396 [FREE Full text] [doi: 10.2337/dc08-1622] [Medline: 19106377]

13. Liu Y, Lu C, Shi L, Liou Y, Lee L, Huang K. Low intensive lifestyle modification in young adults with metabolic syndrome a community-based interventional study in Taiwan. Medicine (Baltimore) 2015 Jun;94(22):e916 [FREE Full text] [doi: 10.1097/MD.0000000000000916] [Medline: 26039125]

14. Piette JD, List J, Rana GK, Townsend W, Striplin D, Heisler M. Mobile health devices as tools for worldwide cardiovascular risk reduction and disease management. Circulation 2015 Nov 24;132(21):2012-2027. [doi: 10.1161/CIRCULATIONAHA.114.008723] [Medline: 26596977]

15. Nelson LA, Coston TD, Cherrington AL, Osborn CY. Patterns of user engagement with mobile- and web-delivered self-care interventions for adults with t2dm: a review of the literature. Curr Diab Rep 2016 Jul;16(7):66 [FREE Full text] [doi: 10.1007/s11892-016-0755-1] [Medline: 27255269]

16. Sawesi S, Rashrash M, Phalakornkule K, Carpenter JS, Jones JF. The impact of information technology on patient engagement and health behavior change: a systematic review of the literature. JMIR Med Inform 2016;4(1):e1 [FREE Full text] [doi: 10.2196/medinform.4514] [Medline: 26795082]

17. Hamine S, Gerth-Guyette E, Faulx D, Green BB, Ginsburg AS. Impact of mHealth chronic disease management on treatment adherence and patient outcomes: a systematic review. J Med Internet Res 2015;17(2):e52 [FREE Full text] [doi: 10.2196/jmir.3951] [Medline: 25803266]

18. Kitsiou S, Paré G, Jaana M, Gerber B. Effectiveness of mHealth interventions for patients with diabetes: an overview of systematic reviews. PLoS One 2017;12(3):e0173160 [FREE Full text] [doi: 10.1371/journal.pone.0173160] [Medline: $\underline{28249025]}$ 
19. Or CKL, Tao D. Does the use of consumer health information technology improve outcomes in the patient self-management of diabetes? a meta-analysis and narrative review of randomized controlled trials. Int J Med Inform 2014 May;83(5):320-329. [doi: 10.1016/j.ijmedinf.2014.01.009] [Medline: 24534118]

20. Sahin C, Courtney KL, Naylor PJ, E Rhodes R. Tailored mobile text messaging interventions targeting type 2 diabetes self-management: a systematic review and a meta-analysis. Digit Health 2019;5:2055207619845279 [FREE Full text] [doi: 10.1177/2055207619845279] [Medline: 31041110]

21. Arambepola C, Ricci-Cabello I, Manikavasagam P, Roberts N, French DP, Farmer A. The impact of automated brief messages promoting lifestyle changes delivered via mobile devices to people with type 2 diabetes: a systematic literature review and meta-analysis of controlled trials. J Med Internet Res 2016;18(4):e86 [FREE Full text] [doi: 10.2196/jmir.5425] [Medline: 27095386]

22. Diabetes Canada Clinical Practice Guidelines Expert Committee, Sherifali D, Berard LD, Gucciardi E, MacDonald B, MacNeill G. Self-management education and support. Can J Diabetes 2018 Apr;42 Suppl 1:S36-S41. [doi: 10.1016/j.jcjd.2017.10.006] [Medline: 29650109]

23. Spruijt-Metz D, O'Reilly GA, Cook L, Page KA, Quinn C. Behavioral contributions to the pathogenesis of type 2 diabetes. Curr Diab Rep 2014 Apr;14(4):475 [FREE Full text] [doi: 10.1007/s11892-014-0475-3] [Medline: 24604714]

24. Bailey KJ, Little JP, Jung ME. Self-monitoring using continuous glucose monitors with real-time feedback improves exercise adherence in individuals with impaired blood glucose: a pilot study. Diabetes Technol Ther 2016 Mar;18(3):185-193. [doi: 10.1089/dia.2015.0285] [Medline: 26885934]

25. Malanda UL, Welschen LMC, Riphagen II, Dekker JM, Nijpels G, Bot SDM. Self-monitoring of blood glucose in patients with type 2 diabetes mellitus who are not using insulin. Cochrane Database Syst Rev 2012 Jan 18;1:CD005060. [doi: 10.1002/14651858.CD005060.pub3] [Medline: 22258959]

26. Majithia AR, Kusiak CM, Armento Lee A, Colangelo FR, Romanelli RJ, Robertson S, et al. Glycemic outcomes in adults with type 2 diabetes participating in a continuous glucose monitor-driven virtual diabetes clinic: prospective trial. J Med Internet Res 2020 Aug 28;22(8):e21778 [FREE Full text] [doi: 10.2196/21778] [Medline: 32856597]

27. Park C, Le QA. The effectiveness of continuous glucose monitoring in patients with type 2 diabetes: a systematic review of literature and meta-analysis. Diabetes Technol Ther 2018 Sep;20(9):613-621. [doi: 10.1089/dia.2018.0177] [Medline: $\underline{30095980]}$

28. Kim YJ, Rhee SY, Byun JK, Park SY, Hong SM, Chin SO, et al. A smartphone application significantly improved diabetes self-care activities with high user satisfaction. Diabetes Metab J 2015 Jun;39(3):207-217 [FREE Full text] [doi: 10.4093/dmj.2015.39.3.207] [Medline: 26124991]

29. Lim S, Kang SM, Kim KM, Moon JH, Choi SH, Hwang H, et al. Multifactorial intervention in diabetes care using real-time monitoring and tailored feedback in type 2 diabetes. Acta Diabetol 2016 Apr 5;53(2):189-198. [doi: 10.1007/s00592-015-0754-8] [Medline: 25936739]

30. Mobula LM, Heller DJ, Commodore-Mensah Y, Walker Harris V, Cooper LA. Protecting the vulnerable during COVID-19: treating and preventing chronic disease disparities. Gates Open Res 2020;4:125 [FREE Full text] [doi: 10.12688/gatesopenres.13181.1] [Medline: $\underline{33117965]}$

31. Liu N, Huang R, Baldacchino T, Sud A, Sud K, Khadra M, et al. Telehealth for noncritical patients with chronic diseases during the COVID-19 pandemic. J Med Internet Res 2020 Aug 07;22(8):e19493 [FREE Full text] [doi: 10.2196/19493] [Medline: 32721925]

32. Yearbook of statistics Singapore, 2019. Department of Statistics Singapore. 2019. URL: https://www.singstat.gov.sg/-/ media/files/publications/reference/yearbook 2019/yos2019.pdf [accessed 2020-11-11]

33. Johanson GA, Brooks GP. Initial scale development: sample size for pilot studies. Educ Psychol Meas 2009 Dec 18;70(3):394-400. [doi: 10.1177/0013164409355692]

34. Lancaster GA, Dodd S, Williamson PR. Design and analysis of pilot studies: recommendations for good practice. J Eval Clin Pract 2004 May;10(2):307-312. [doi: 10.1111/j.2002.384.doc.x] [Medline: $\underline{15189396}$ ]

35. American Diabetes Association. Glycemic targets: standards of medical care in diabetes—2020. Diabetes Care 2020 Jan;43(Suppl 1):S66-S76. [doi: 10.2337/dc20-S006] [Medline: 31862749]

36. Davies MJ, D'Alessio DA, Fradkin J, Kernan WN, Mathieu C, Mingrone G, et al. Management of hyperglycaemia in type 2 diabetes, 2018. a consensus report by the American Diabetes Association (ADA) and the European Association for the Study of Diabetes (EASD). Diabetologia 2018 Dec;61(12):2461-2498. [doi: 10.1007/s00125-018-4729-5] [Medline: $\underline{30288571]}$

37. Diabetes mellitus - MOH clinical practice guidelines 1/2014. Ministry of Health, Singapore. 2014. URL: https://www. moh.gov.sg/docs/librariesprovider4/guidelines/cpg diabetes-mellitus-booklet---jul-2014.pdf [accessed 2021-03-19]

38. Expert Consultation WHO. Appropriate body-mass index for Asian populations and its implications for policy and intervention strategies. Lancet 2004 Jan 10;363(9403):157-163. [doi: 10.1016/S0140-6736(03)15268-3] [Medline: 14726171]

39. Holman RR, Paul SK, Bethel MA, Matthews DR, Neil HAW. 10-year follow-up of intensive glucose control in type 2 diabetes. N Engl J Med 2008 Oct 09;359(15):1577-1589. [doi: 10.1056/NEJMoa0806470] [Medline: 18784090] 
40. Ismail-Beigi F, Craven T, Banerji MA, Basile J, Calles J, Cohen RM, ACCORD trial group. Effect of intensive treatment of hyperglycaemia on microvascular outcomes in type 2 diabetes: an analysis of the ACCORD randomised trial. Lancet 2010 Aug 07;376(9739):419-430 [FREE Full text] [doi: 10.1016/S0140-6736(10)60576-4] [Medline: 20594588]

41. ADVANCE Collaborative Group, Patel A, MacMahon S, Chalmers J, Neal B, Billot L, et al. Intensive blood glucose control and vascular outcomes in patients with type 2 diabetes. N Engl J Med 2008 Jun 12;358(24):2560-2572. [doi:

10.1056/NEJMoa0802987] [Medline: 18539916]

42. ACCORD Study Group, ACCORD Eye Study Group, Chew EY, Ambrosius WT, Davis MD, Danis RP, et al. Effects of medical therapies on retinopathy progression in type 2 diabetes. N Engl J Med 2010 Jul 15;363(3):233-244 [FREE Full text] [doi: 10.1056/NEJMoa1001288] [Medline: 20587587]

43. Zoungas S, Chalmers J, Neal B, Billot L, Li Q, Hirakawa Y, ADVANCE-ON Collaborative Group. Follow-up of blood-pressure lowering and glucose control in type 2 diabetes. N Engl J Med 2014 Oct 09;371(15):1392-1406. [doi: 10.1056/NEJMoa1407963] [Medline: 25234206]

44. Zabala A, Darsalia V, Holzmann MJ, Franzén S, Svensson A, Eliasson B, et al. Risk of first stroke in people with type 2 diabetes and its relation to glycaemic control: a nationwide observational study. Diabetes Obes Metab 2020 Feb;22(2):182-190. [doi: 10.1111/dom.13885] [Medline: $\underline{\text { 31576643] }}$

45. American Diabetes Association. Obesity management for the treatment of type 2 diabetes: standards of medical care in diabetes-2020. Diabetes Care 2020 Jan;43(Suppl 1):S89-S97. [doi: 10.2337/dc20-S008] [Medline: $\underline{31862751]}$

46. Jensen MD, Ryan DH, Apovian CM, Ard JD, Comuzzie AG, Donato KA, et al. 2013 AHA/ACC/TOS guideline for the management of overweight and obesity in adults: a report of the American College of Cardiology/American Heart Association Task Force on Practice Guidelines and The Obesity Society. J Am Coll Cardiol 2014 Jul 1;63(25 Pt B):2985-3023 [FREE Full text] [doi: 10.1016/j.jacc.2013.11.004] [Medline: 24239920]

47. Wing RR, Lang W, Wadden TA, Safford M, Knowler WC, Bertoni AG, et al. Benefits of modest weight loss in improving cardiovascular risk factors in overweight and obese individuals with type 2 diabetes. Diabetes Care 2011 Jul;34(7):1481-1486 [FREE Full text] [doi: 10.2337/dc10-2415] [Medline: 21593294]

48. Look AHEAD Research Group, Pi-Sunyer X, Blackburn G, Brancati FL, Bray GA, Bright R, et al. Reduction in weight and cardiovascular disease risk factors in individuals with type 2 diabetes: one-year results of the look AHEAD trial. Diabetes Care 2007 Jun;30(6):1374-1383 [FREE Full text] [doi: 10.2337/dc07-0048] [Medline: 17363746]

49. Bonoto BC, de Araújo VE, Godói IP, de Lemos LLP, Godman B, Bennie M, et al. Efficacy of mobile apps to support the care of patients with diabetes mellitus: a systematic review and meta-analysis of randomized controlled trials. JMIR Mhealth Uhealth 2017 Mar 01;5(3):e4 [FREE Full text] [doi: 10.2196/mhealth.6309] [Medline: 28249834]

50. Martos-Cabrera MB, Velando-Soriano A, Pradas-Hernández L, Suleiman-Martos N, Cañadas-De la Fuente GA, Albendín-García L, et al. Smartphones and apps to control glycosylated hemoglobin (HbA1c) level in diabetes: a systematic review and meta-analysis. J Clin Med 2020 Mar 04;9(3):693 [FREE Full text] [doi: 10.3390/jcm9030693] [Medline: 32143452]

51. Cui M, Wu X, Mao J, Wang X, Nie M. T2DM self-management via smartphone applications: a systematic review and meta-analysis. PLoS One 2016;11(11):e0166718 [FREE Full text] [doi: 10.1371/journal.pone.0166718] [Medline: 27861583]

52. Koot D, Goh PSC, Lim RSM, Tian Y, Yau TY, Tan NC, et al. A mobile lifestyle management program (GlycoLeap) for people with type 2 diabetes: single-arm feasibility study. JMIR Mhealth Uhealth 2019 May 24;7(5):e12965 [ㅌREE Full text] [doi: $\underline{10.2196 / 12965}$ ] [Medline: $\underline{31127720}$ ]

53. Republic of Singapore government gazette - acts supplement. Singapore Statutes Online. 2020. URL: https://sso.agc.gov.sg/ Act/COVID19TMA2020 [accessed 2020-11-11]

54. Tison GH, Avram R, Kuhar P, Abreau S, Marcus GM, Pletcher MJ, et al. Worldwide effect of COVID-19 on physical activity: a descriptive study. Ann Intern Med 2020 Nov 03;173(9):767-770 [FREE Full text] [doi: 10.7326/M20-2665] [Medline: 32598162]

55. Mattioli AV, Ballerini Puviani M, Nasi M, Farinetti A. COVID-19 pandemic: the effects of quarantine on cardiovascular risk. Eur J Clin Nutr 2020 Jun;74(6):852-855 [FREE Full text] [doi: 10.1038/s41430-020-0646-z] [Medline: 32371988]

56. Mattioli AV, Sciomer S, Cocchi C, Maffei S, Gallina S. Quarantine during COVID-19 outbreak: changes in diet and physical activity increase the risk of cardiovascular disease. Nutr Metab Cardiovasc Dis 2020 Aug 28;30(9):1409-1417 [FREE Full text] [doi: 10.1016/j.numecd.2020.05.020] [Medline: 32571612]

57. Hoerster KD, Lehavot K, Simpson T, McFall M, Reiber G, Nelson KM. Health and health behavior differences: U.S. military, veteran, and civilian men. Am J Prev Med 2012 Nov;43(5):483-489. [doi: 10.1016/j.amepre.2012.07.029] [Medline: 23079170]

58. Meadows SO, Engel CC, Collins RL, Beckman RL, Cefalu M, Hawes-Dawson J, et al. 2015 Department of Defense health related behaviors survey (HRBS). Rand Health Q 2018 Oct;8(2):5 [FREE Full text] [Medline: 30323988]

59. Sepah SC, Jiang L, Peters AL. Long-term outcomes of a web-based diabetes prevention program: 2-year results of a single-arm longitudinal study. J Med Internet Res 2015 Apr 10;17(4):e92 [FREE Full text] [doi: 10.2196/jmir.4052] [Medline: 25863515] 


\section{Abbreviations}

BMI: body mass index

CGM: continuous glucose monitoring

$\mathbf{H b A}_{1 \mathbf{c}}$ : glycated hemoglobin $\mathrm{A}_{1 \mathrm{c}}$

mHealth: mobile health

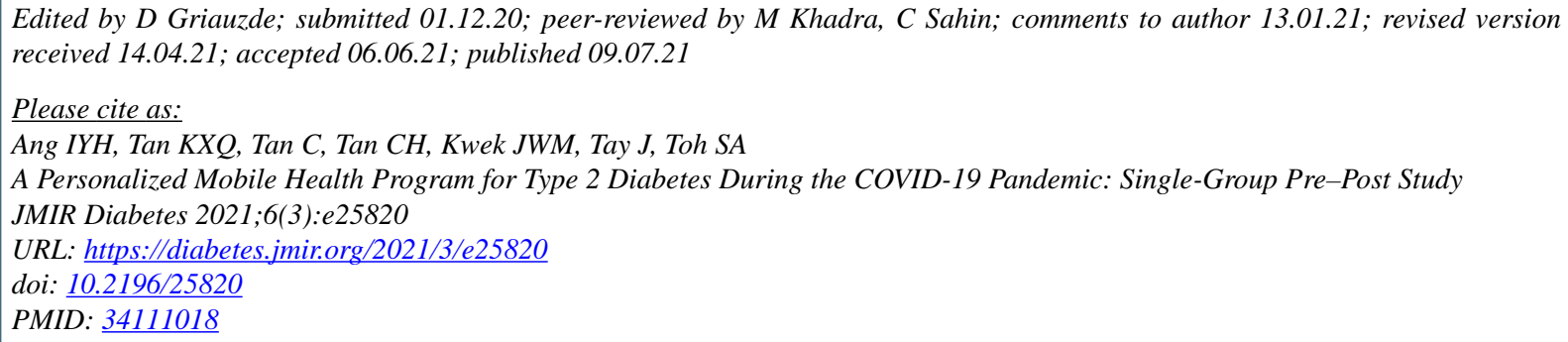

CIan Yi Han Ang, Kyle Xin Quan Tan, Clive Tan, Chiew Hoon Tan, James Wei Ming Kwek, Joanne Tay, Sue Anne Toh. Originally published in JMIR Diabetes (https://diabetes.jmir.org), 09.07.2021. This is an open-access article distributed under the terms of the Creative Commons Attribution License (https://creativecommons.org/licenses/by/4.0/), which permits unrestricted use, distribution, and reproduction in any medium, provided the original work, first published in JMIR Diabetes, is properly cited. The complete bibliographic information, a link to the original publication on https://diabetes.jmir.org/, as well as this copyright and license information must be included. 